\title{
Profissionalização continuada do docente da educação superior: desafios e possibilidades
}

\section{On-Going training for university professors in the pedagogic area: challenges and possibilites}

\author{
Lea das Graças Camargo ANASTASIOU*
}

\begin{abstract}
Resumo: Ao analisar a situação dos que atuam hoje nas salas de aula da universidade, verificou-se que, com exceção dos docentes provenientes das Licenciaturas e Pedagogia, a grande maioria dos professores universitários não conta com a formação sistêmica necessária à construção de uma identidade profissional para a docência. Diagnóstico inicial realizado em uma instituição universitária apontou o desconhecimento, por esses professores, da proposta pedagógica vigente e da teoria pedagógica vigente e da teoria pedagógica em ação; trabalho docente individualizado e fragmentado; distância das disciplinas teóricas das práticas; predominância de um modelo jesuítico de aula expositiva, cópia e exercícios de verificação. Esses e outros elementos foram tomados como ponto de partida e de chegada de um processo de Profissionalização Continuada que, constituído por duas experiências diferentes, mas tendo em comum a proposta de mudanças por aproximações processuais, sucessivas, por meio de estudos e investigações, objetivaram possibilitar aos referidos docentes um processo de análise, estudo, discussões e construções coletivas que lhes propiciasse a formação contínua essencial ao exercício do magistério. Vários elementos foram determinantes desse Processo de Profissionalização, dentes eles: o conhecimento da realidade, a abrangência de uma proposta coletiva e institucional, a presença os coordenadores dos cursos ou departamentos, o fator tempo, as condições concretas de efetivação, a definição de elementos da teoria didática, a participação dos alunos e o reconhecimento da necessidade de um trabalho colegiado, participativo, cooperativo, entre os sujeitos do processo. A investigação, caracterizada como uma pesquisa-ação, permitiu a constatação de que os pro-
\end{abstract}

\footnotetext{
* Doutora em Didática pela USP, com pós-doutorado em Profissionalização Continuada de Docentes Universitários. Professora do Programa de Mestrado em Educação da UNOESC. Email: leagc@matrix.com.br
}

Olhar de professor, Ponta Grossa, 8(1): 09-22, 2005. 
cessos de profíssionalização continuada vivenciados constituem espaços institucionais de fortalecimento das identidades pessoais e profissionais e da própria categoria docente. Resultam, tais processos, em proveito para os sujeitos envolvidos e para o próprio processo de ensino e aprendizagem, possibilitando sistematizações importantes acerca da ação docente universitária hoje necessária.

Palavras-chave: docência, profíssionalização continuada, saber didático, processo de ensino e aprendizagem

\begin{abstract}
Analyzing the situation of those who teach in universities, it was noted that, with the exception of teachers from Teaching and Pedagogy courses, most university professors do not have the systematic formation needed for building up a professional identity in teaching. This initial diagnostic was done in a university and showed that these professors were unaware of the current teaching propositions and the teachig theory currently in use; work on teaching is individual and fragmentary; there is a gap between theoretical and practical subjects; there is the predominance of a jesuitic model of expository class, with copying and exercises done for verification. These and other elements were taken as the starting point and the aim of an on-going process of professionalization which constituted two different experiences though having in common a proposition for changes through processual and successive approaches through studies and investigations. For the professors, this facilitated analysis, study, discussions and collective development which propitiated a continuous formation so essential to teaching. Several were the determining factors in this process of professionalization: knowlege of reality, the range of a collective and institutional proposition, the presence of coordinators belonging to the courses or departments, the time factor, concrete conditions for putting this into effect, definition of the elements of didactic theory, student participation and acknowledgement of the need for a collegiate work, participative and cooperative among the subjects of this process. This study, characterized as a research in action, showed that the experiences of on-going professionalization make room for the strenghtening of personal and professional identity of professors in an institution. Such processes result in a betterment for all the subjects concerned and for the teaching process itself, allowing for much needed important systems to appear related to the work of the university professor.
\end{abstract}

Key words: teaching, on-going professionalization, didactic knowledge, learning and teaching process

É sabido que os elementos referentes à formação para o magistério não têm sido exigidos para o exercício da docência universitária. Essa formação, quando ocorre, limita-se ao cursar de uma disciplina de 60 horas, chamada Metodologia do Ensino Superior, na pós-graduação, 
constituindo-se, para a maioria dos profissionais que atuam nas universidades, a principal experiência de sistematização de conhecimentos para o dar aulas.

Temos então uma área de saber essencial à docência, o saber didático, reduzido à uma amostragem insuficiente para o exercício de uma profissão. Basta imaginar um profissional de outras áreas (da Saúde, das Tecnológicas) que tivesse estudado apenas essa carga horária, para imaginarmos as probabilidades de desempenho que ele efetivaria.

Buscamos então diferenciar ocupação de profissão, visando identificar se em sala de aula universitária temos ocupantes da docência ou profissionais docentes.

Nas profissões de nível universitário, o processo de construção da identidade é iniciado nos estudos dos conteúdos formais e sistemáticos na graduação, na definição dos objetivos profissionais, na construção de um ideal, na convivência com uma regulamentação profissional, com um código de ética, buscando reconhecimento social e a participação em entidades de classe: esses elementos se sistematizam com o passar dos anos, na prática profissional. Ocorre um domínio progressivo dos conhecimentos da área, que incluem os seguintes saberes: saber o quê? Saber como? Saber para que? Tais saberes vão gradativamente se sistematizando, favorecendo a construção de um desempenho autônomo e competente, neces- sário ao exercício da profisssão.

Quando se é capaz tanto de dar conta do habitual quanto de desenvolver continuamente encaminhamentos para resolver problemas, solucionando questões e situações novas, inusitadas, complexas e desafiadoras, em re-arranjos das aprendizagens efetivadas, diz-se que se atua como um profissional, com autonomia e capacidade de prosseguir contribuindo para uma caminhada de transformação de si, da área onde atua e da própria realidade. Para isso, não basta ter "sofrido" um treinamento ocupacional, no qual apenas se aprende a solucionar situações previsíveis, treináveis, utilizando-se dos modelos operacionais existentes.

Analisando a situação dos que atuam hoje nas salas de aula da universidade, verifica-se que, com exceção dos docentes provenientes das Licenciaturas e Pedagogia, a grande maioria dos professores universitários não contou com a formação sistemática, necessária à construção de uma identidade profissional para a docência. Embora se encontrem dando aulas, nem sempre esses professores dominam as condições necessárias para atuar como profissionais docentes.

Nesse contexto se inserem as experiências que denominamos de profissionalização continuada: profissionalização, porque se busca possibilitar tal nível de autonomia que os docentes sintam-se capazes de solucionar novas situações além das

Olhar de professor, Ponta Grossa, 8(1): 09-22, $2005 . \overline{11}$ 
habituais; ou debruçar-se sobre elas com novos olhares, construindo e avançando nos processos de identidade pessoal e profissional, revendo os elementos determinantes da profissão docente, seus nexos constituintes, assumindo a condução dos Projetos Pedagógicos das Instituições e Cursos onde atuam, vinculando-se coletivamente ao grupo institucional e, sobretudo, vivenciando a docência como um processo em continuidade, de onde usamos a expressão complementar. Também consideramos continuidade porque os profissionais das diferentes áreas, que exercem a ocupação de dar aulas, já possuem saberes sobre a docência, saberes esses adquiridos com a experiência como docentes ou como alunos. Tais saberes são tomados como fundantes nos processos, pois como saberes da prática revelam uma teoria sobre a qual o professor, geralmente, não se debruçou, para confirmar ou contradizer: é preciso que ela seja, para que se possa superá-la. desvelada

A expressão Profissionalização Continuada, sobretudo, carrega em si o movimento necessário à formação contínua, essencial à profissão docente que, por trabalhar com seres em mudança e com o conhecimento em constante alteração, é carregada de imprevisibilidade, alterações, singularidade, incerteza, novidade, dilema, conflito e instabilidade, exigindo a flexibilidade mental como um dos elementos fundamentais.

\section{CONTEXTOS DE PROFISSIONA- LIZAÇÃOCONTINUADA}

Para nossa reflexão, estaremos pontuando elementos de duas vivências, buscando sistematizar elementos da teoria então construída. Embora tratem de situações institucionais contextualizadas e portanto, únicas e irrepetíveis, contêm especificidades que nos permitem um refletir e um sistematizar que destacaremos.

As situações vivenciadas caracterizam-se como uma experiência com a quase totalidade dos docentes de uma instituição (média de 80\%). É fundamental destacar que, nessa experiência, condições concretas de efetivação do processo foram garantidas: clima institucional de total valorização do processo e das participações; espaço adequado e materiais para todos os participantes; envolvimento dos coordenadores dos cursos; pagamento de $50 \%$ das horas dos encontros aos professores participantes, além de outros elementos como construção do plano de carreira, com valorização da participação em aperfeiçoamentos. Efetivou-se aí um processo de pesquisa-ação com a participação de uma equipe institucional que, posteriormente, veio compor o Núcleo de Assessoria Pedagógica Institucional, o qual mantém um processo de análise, estudos, discussões e construções coletivas, assim como um espaço de realimentação da ação coletiva pela reconstrução dos Proje- 
tos Pedagógicos, sejam eles Institucionais ou de Cursos, Planos ou Programas de Aprendizagem. Decisões sobre metodologia e avaliação também ficaram sob a responsabilidade do referido Núcleo.

Esse grupo reuniu-se durante dois anos (2001 e 2002), uma vez por mês. No primeiro ano, o processo centrouse nas questões da prática, levantadas no diagnóstico, e tomou a relação teoria/prática e os elementos da teoria da complexidade como base dos processos vivenciados. No segundo ano (2001), a forma de organização diferenciou-se e os professores inscreveram-se em três oficinas de investigação de situações de sala de aula, conforme temas por eles definidos: Avaliação, Relação Professor e Aluno e Interdisciplinaridade. Foram dois anos de trabalho sistemático do qual resultaram 38 projetos de investigação de sala de aula universitária, efetivados individualmente, ou em duplas ou grupos, com trocas entre os participantes.

Uma segunda experiência envolve uma instituição com maior número de docentes, uma média de 600 professores. Devido a esse número, a instituição - através do seu Centro de Apoio Pedagógico - optou por iniciar o processo, em 2002, por adesão voluntária, com dois grupos de 40 professores, um dos quais manteve-se em aprofundamento até 2003. Além disso, houve o envolvimento de mais dois grupos de 40 professores, que estão sendo mediados por docentes que participaram das turmas de 2002 e se constituíram como um grupo de multiplicadores. Esse grupo passou a complementar a equipe do CAP, Centro de Apoio Pedagógico, através de ação sistemática, reunindo-se mensalmente para estudos e análise das vivências dos últimos encontros e para o planejamento do próximo encontro previsto.

Nas duas vivências citadas, a situação curricular existente é predefinida: currículo organizado em grade ou coleção e com vários elementos comuns, dos quais pontuamos: desconhecimento da proposta pedagógica vigente e da teoria pedagógica em ação; visão de conhecimento centrada na especialização (visão moderna); trabalho docente individualizado e fragmentado; distância entre as disciplinas teóricas e as práticas; modelo curricular com estágio no final do curso; dificuldades no envolvimento e relacionamento com os alunos; contrato por horas aulas; predominância de um modelo jesuítico de aula expositiva, cópia e exercícios de verificação, além do uso predominantemente punitivo e classificatório da avaliação.

Esses e outros elementos levantados no diagnóstico inicial foram tomados como ponto de partida e de chegada do processo de Profissionalização Continuada, pois em processos de pesquisa-ação as necessidades dos sujeitos funcionam como determinantes fundamentais.

As duas experiências têm em co- 
mum proporem mudanças por aproximações processuais, sucessivas, por meio de estudos e investigações, visando a preparar o docente para atuar com autonomia e competência na ação de ensinar, mesmo com as dificuldades de processos integrativos próprios do modelo de grade curricular e de estrutura departamental.

ELEMENTOS DETERMINANTES DO PROCESSO DE PROFISSIONALIZAÇÃO: PONTOS DE RETOMADA PARA UMA REFLEXÃO INICIAL

Conforme já destacado em publicações anteriores, temos pontuado elementos que vêm compondo os processos de profissionalização vivenciados, tomando-os como ponto de partida e de discussão da proposta a ser colocada em ação. A importância do primeiro desses elementos, o $\mathrm{co}$ nhecimento da realidade, está principalmente no fato de que o diagnóstico, o conhecimento e a priorização dos problemas da realidade, pelo coletivo, possibilitam ganho de tempo e a centralização de questões a serem trabalhadas, estimulam a criticidade, a compreensão e o envolvimento do grupo, atendendo tanto os objetivos de uma pesquisa-ação quanto os de um processo de ação pedagógica.

Outro elemento a ser considerado é a abrangência: uma proposta coletiva e institucional que inclua todo o coletivo docente tem maiores chances de possibilitar mudanças significati- vas do que ações individuais. Instituições com grande número de docentes têm iniciado com alguns grupos e depois vão estendendo o processo aos demais. Nos contextos em que apenas uma parcela do colegiado institucional participa, há dois aspectos a considerar: a dificuldade de se estabelecer uma mudança mais abrangente (por alguns professores de cada departamento ou curso); e, em contrapartida, a disseminação de um novo modo de pensar, participar, ensinar, avaliar, que se inicia institucionalmente. Ressaltamos a dificuldade de se estabelecer o acompanhamento, em casos de inscrição aleatória dos docentes participantes, em relação aos cursos em que atuam.

A presença dos coordenadores de cursos ou departamentos nos processos tem sido pontuada pelos participantes: como ocupam cargos decisórios, a implantação de modificações compreendidas e assumidas pelas coordenações fica facilitada.

Outro elemento fundamental refere-se à questão tempo. Não se trata de um processo informativo, a ser resolvido numa palestra de algumas horas. Assim como é impossível capacitar-se profissional em qualquer área numa palestra, o mesmo ocorre na preparação inicial ou continuada da docência.Um processo de preparação pedagógica deve estabelecer objetivos, etapas, encaminhamentos e re-encaminhamentos ao longo de um tempo pré-estabelecido, suficiente para enfrentar-se os problemas di- 
agnosticados, analisados e acompanhados.

As condições concretas de efetivação das mudanças devem ser dadas. Uma vez percebidas, discutidas e processadas as alterações necessárias, os docentes que se dispuserem a assumi-las devem contar com o apoio logístico apropriado. Embora estejamos advogando uma abrangência coletiva do trabalho de profissionalização, é preciso destacar a validade de processos de adesão voluntários, pois não se faz mudança por decreto. Retaliações de qualquer espécie só prejudicam o avanço na construção de um coletivo inovador.

A definição de elementos da teoria didática, essenciais a uma construção da relação professor, aluno e conhecimento na educação superior, estará diretamente ligada ao diagnóstico inicial, variando de equipe para equipe de trabalho. A vivência desses elementos já ocorre nas salas de aula e a análise é a base para o confronto da teoria com a prática. $\mathrm{O}$ docente já possui um "habitus" formado. Como sujeito de processo individual e da caminhada coletiva, sua voz, sua experiência, sua adesão e rejeição são essenciais na definição dos caminhos. A prática profissional existente deve ser o ponto de partida dos trabalhos, tanto para a mobilização quanto para a construção e a elaboração processual da síntese dos conhecimentos.

Há que se considerar a importância da participação dos alunos, de sua voz e percepção, no processo. Essa participação pode se dar através dos instrumentos de avaliação institucional, que nos possibilitam elementos de referência para análise da instituição e da ação docente, como vista pelo alunado.

$\mathrm{O}$ destaque aos sujeitos do processo, professores e alunos, evidencia a necessidade de se encarar os desafios de um trabalho colegiado, participativo, cooperativo, entre os sujeitos dos processos de profissionalização. Inicialmente, destacamos o desafio quanto ao trabalho em parceria: enquanto participantes de corpo docente das instituições de ensino superior, tem sido historicamente reforçado entre nós um trabalho individual, individualizado, fragmentado, disciplinar, evitando-se relações de mútua dependência e trocas sistemáticas.

Ou seja, pontuamos que, além do docente das diferentes áreas não haver tido oportunidades sistemáticas de se profissionalizar na docência, o hábito do trabalho parcelarizado está

\footnotetext{
${ }^{1}$ Hábityus segundo Perrenoud (1993, p. 39-40), são esquemas de ação conservados e que funcionam na prática, aos quais o professor recorre, sem necessidade de explicitação. Como uma espécie de computador, tenta constantemente integrar os dados (o que acontece, o que já aconteceu, o que deveria acontecer, e o que ainda se pode fazer), transformando-os numa ação mais ou menos eficaz e reversível.
}

Olhar de professor, Ponta Grossa, 8(1): 09-22, 2005. 
altamente implantado entre nós. Do planejamento à avaliação, passando pela execução, temos a efetivação da ação individual e solitária do docente. Atuando num mesmo curso e/ou semestre / ano letivo, é pouco comum o trabalho solidário ou complementar, baseado em troca.

Daí a importância das reflexões que se seguem.

\section{DESAFIO DOS PROCESSOS DE VINCULAÇÃO SUPERANDO A INDIVIDUALIZAÇÃOE COMPETIÇÃO}

Nos processos de profissionalização dos quais já participamos, colocamos como elemento essencial o principio de, coletivamente, se efetivarem diagnósticos, estudos, discussões, problematizações, sínteses, de forma a vivenciar metodologicamente processos interativos. Vivenciar estratégias de ensinagem ${ }^{2}$ situa-se como uma forma altamente possibilitadora de um fazer diferenciado: os docentes vão vivendo, construindo sínteses acerca das formas do fazer docente, reforçando buscas, dúvidas, assertivas e dificuldades, nos processamentos grupais.

Nas análises e sínteses propos- tas no Processo de Profissionalização, são importantes tanto os momentos individuais de debruçar-se sobre o objeto de estudo, quanto os momentos grupais. É fundamental a organização, a preparação cuidadosa, o planejamento compartilhado e mutuamente comprometido, uma vez que todos atuarão ativamente: os objetivos, as normas, as formas de ação, os papéis, as responsabilidades devem estar explicitados e compactuados.

Três elementos interrelacionados são essenciais em processos de profissionalização: o desenvolvimento pessoal, ao se destacarem os processos de produção da vida do professor; o desenvolvimento profissional, ao se destacarem os elementos determinantes da produção da profissão docente; e o desenvolvimento organizacional, ao se analisar e propor a produção da instituição, pelo seu coletivo docente. O cerne de todos eles é a identidade dos professores, lembrando que "o professor é uma pessoa; e uma parte importante da pessoa é o professor" (NIAS JENIFFER inNÓVOA, 1992, p. 15), por isso a importância das descrições feitas pelos professores sobre as formas de atuar em sala de aula. Elas possibilitam um confronto sobre a

\footnotetext{
${ }^{2}$ A expressão ensinagem foi inicialmente explicitada em: ANASTASIOU, L. G. C. Metodologia do ensino superior: da prática docente a uma possível teoria pedagógica. Curitiba: Ibpex, 1998. Termo adotado para significar uma situação de ensino da qual necessariamente decorra a aprendizagem, sendo a parceria entre professor e alunos condição fundamental para o enfrenta-mento do conhecimento necessário à formação do aluno, durante o cursar da graduação.
} 
historicidade da constituição da universidade brasileira e a identificação individual e coletiva- quanto à organização curricular, à prática em sala de aula e à teoria que a sustenta.

Esses elementos aparecem claramente nas atividades grupais, que, a nosso ver, constituem-se num desafio a ser reconhecido e enfrentado. Reforça-se aí o princípio da aprendizagem como um ato social, necessitando da mediação do outro, facilitador do processo. Esse outro, que estabelece a mediação entre o aprendiz e o objeto de estudo, pode ser um professor, os colegas, ou um texto; ou a mediação pode efetivar-se através de estratégias ${ }^{3}$ como um vídeo, um caso a ser solucionado, um tema a ser debatido. Lembramos que trabalhar num grupo é diferente de fazer parte de um conjunto de pessoas, sendo fundamental a interação, o compartilhar, o respeito à singularidade, à habilidade de lidar com o outro em sua totalidade, incluindo suas emoções. Isso exige autonomia e maturidade, algo a ser construído tanto entre docentes, como entre alunos universitários, uma vez que tais não vêm com estes atributos das experiências anteriores. $\mathrm{O}$ que caracteriza o grupo não é a junção dos participantes, mas o desenvolvimento inter e intrapessoal possibilitado pelos objetivos compartilhados e diferencia- do pelos diagnósticos, pelo processo objetivado, pelas estratégias selecionadas e pelo seu processamento.

Embora as formas de organização grupal se alterem nos momentos do processo de profissionalização, em todos está presente o desenvolvimento da habilidade de conversar. Etimologicamente, a palavra é composta de dois elementos: con, que significa juntos; e versar, que quer dizer mudar. Conversar com o outro pressupõe a abertura para mudar junto com o outro; de uma conversa bem sucedida ocorrerá alguma mudança no pensar, no perceber, sentir ou agir dos envolvidos (OSÓRIO, 2003).

È por isso que a vivência do processo é tão importante quanto os elementos conceituais; inclui, assim, os conteúdos procedimentais ou atitudinais trabalhados, pois habilidades de trabalho, devidamente desenvolvidas, auxiliam no desabrochar da inteligência relacional, que abarca, segundo Osório (2003), a inteligência intrapessoal (autoconhecimento emocional, controle emocional e automotivação) e a inteligência interpessoal (reconhecimento de emoções de outras pessoas e habilidades em relacionamentos interpessoais). É essencial para a inteligência relacional a "capacidade dos indivíduos serem competentes na

${ }^{3}$ A respeito do ensinar, do apreender e das estratégias, ver: ANASTASIOU, L. G. C.; PESSATE, L. A. (Orgs.). Processos de ensinagem na universidade: dos pressupostos às estratégias de trabalho em aula. Joinville: Univille, 2003.

Olhar de professor, Ponta Grossa, 8(1): 09-22, 2005. 
interação com outros seres humanos no contexto grupal em que atuam" (OSÓRIO, 2003,p. 65-66). ${ }^{4}$

A dificuldade de se relacionar em sala de aula com os alunos em geral e com alguns em particular tem aparecido em todos os grupos vivenciados. É importante possibilitar aos docentes ferramentas de ações e interações com os sujeitos com quem convivem cotidianamente. A ação de equipes integradas, dispostas a conversar e, juntas, mudar, é altamente desafiante. Inicialmente e até que todos se soltem em atividades grupais, as contribuições de cada participante podem ficar mais restritas às discussões do pequeno grupo, expondo menos cada um. Quando ainda ocorre uma inibição no grupo, no momento da socialização da síntese costuma ocorrer a indicação, pelo próprio grupo, de colegas que já trazem desenvolvidas habilidades de exposição oral, desenvoltura e liderança. Caberá uma leveza na condução do processo, deixando claro que o espaço de profissionalização é o lugar do treino, da aprendizagem, onde o erro não fere. Como hipótese incompleta, deve ser a referência para a reconstrução e superação de dificuldades.

Participar de grupos de estudo permite o desenvolvimento de uma serie de papéis que auxiliam na construção da autonomia, do autoconhe- cimento, do lidar com o diferente, da exposição e da contraposição, do divergir, do sintetizar, resumir; enfim, de habilidades necessárias ao desempenho do papel docente, visando à autonomia crescente de alunos e professores.

O clima de trabalho é fundamental: é preciso estabelecer processos de parceria nos grupos, situando os papéis a serem desempenhados como articuladores na direção da consecução dos objetivos. Habitualmente são necessárias contribuições no sentido de coordenar a participação de todos. A definição dos papéis pode ser feita por escolha, indicação, sorteio, eleição ou outro critério como o rodízio. Variar o desempenho de papéis deve ser norteador do clima grupal, visando ao crescimento e autonomia crescente de todos. Um elemento auxiliar é, reiteramos, a reflexão de que se trata de um processo e de um espaço de sala de aula, no qual o erro não fere, pois é onde as aprendizagens podem ser vividas, refletidas, reformuladas e sistematizadas.

Conduzidas dessa forma e devidamente processadas, as atividades grupais possibilitam ao docente um contínuo crescimento pessoal e profissional: inicia-se um processo de responsabilidade coletiva pelo desempenho grupal e pessoal, pelos estudos preliminares, pela defesa de idéi-

\footnotetext{
${ }^{4}$ Para uma melhor compreensão desses conceitos vide OSÓRIO, L. C. Psicologia grupal: uma nova disciplina pra o advento de uma era. Porto Alegre: Artmed, 2003.
} 
as, pela produção e pelo respeito às normas estabelecidas. Normas que incluem cuidados como a atitude do "conversar", de respeitar as idéias do outro, negociar, ouvir, esperar a vez de falar, além do desempenho de algum papel específico que seja atribuído ao docente pelo grupo.

Um elemento de forte marca no processo de dois anos vivenciado pelo primeiro grupo citado foi a experiência da construção do memorial ${ }^{5}$. Trata-se de um processo identitário que se constrói pelo significado que cada professor, como autor e ator, confere às atividades de sua vida escolar, o que inclui valores, modo de situar-se no mundo, história de vida, representações construídas, saberes, angústias, receios profissionais. A identidade pessoal e profissional é também buscada, em sua vertente histórica $^{6}$, desde os estudos iniciais no processo, acerca da ciência, conhecimento, saber escolar, os quais são relacionados com as visões modernas e pós-modernas e suas decorrências nos currículos universitários e na ação docente. Dessa ação decorre determinada visão de mundo, de conhecimento e saber escolar, básicos em nossas áreas de atuação. Essa base de historicidade tem sido auxili- ar na inter-relação do desenvolvimento pessoal, profissional e organizacional, pontos de partida e de chegada das ações propostas. É um processo de construção do sujeito historicamente situado" (PIMENTA, 1999, p. 164), que se efetiva a partir de diferentes atividades a serem vivenciadas (estudos de textos, montagem de quadros comparativos, análise de vídeos, jogos, vivências grupais, descrição de memorial, discussões, análise de disciplinas, de currículos, etc).

$\mathrm{Na}$ reflexão coletiva cada um se coloca na roda, se deixa conhecer, se expõe, em processos de reconstrução da experiência com várias formas de interação, nos quais sujeitos e situação são mutuamente modificados e as contribuições da teoria, com suas leis, princípios e categorias de análise são aceitas, visando ao movimento de desvelar, pela prática, a ação. Realizase um processo de investigação da prática, de forma intencional, problematizando-a em seus resultados e no processo, encarando-a como um desafio a ser enfrentado e vivenciado. Fazer-se professor nos processos de profissionalização continuada requer intencionalidade, envolvimento, disponibilidade para mudança, espaço

\footnotetext{
${ }^{5}$ A respeito da construção do memorial vide ANASTASIOU, L. G. C. In: VIELLA, M. A. (Org.). Tempos e espaços de formação. Chapecó: Argos: 2003.

${ }^{6}$ A respeito dos modelos históricos de influência, vide ANASTASIOU, L. G. C. Metodologia de ensino na universidade brasileira: elementos de uma trajetória. In: CASTANHO, M. E. e CASTANHO, S. Temas e textos em metodologia do ensino superior. Campinas: Papirus, 2001.
}

Olhar de professor, Ponta Grossa, 8(1): 09-22, 2005. 
institucional, coragem, riscos, flexibilidade mental, enfrentamento de alterações previsíveis e imprevisíveis...

DESENVOLVIMENTO PESSOAL PROFISSIONAL E INSTITUCIONAL: UMA TEIA A SER CONSTRUÍDA

Saber-se docente universitário é saber-se parte de uma categoria profissional que tem a aula como espaço privilegiado na relação com os pares, os alunos, para processos de parceria na conquista, tradução, construção, aplicação e sistematização de saberes de diferentes áreas, possibilitando a formação de profissionais que atuarão na realidade, construindo-a e transformando-a, na medida que se constroem e se transformam.

Fazer parte de um coletivo institucional implica co-reponsabilizar-se pelos resultados obtidos, com todos e por todos, na efetivação de um Projeto Pedagógico Institucional e de Curso, no qual atuamos com uma parcela de um quadro teórico-prático global, seja ainda disciplinarmente, nos casos dos currículos organizados em grade ou coleção, seja integradamente, nos casos dos currículos globalizantes.

A contribuição de cada um é referente à especialidade que domina. Mas, hoje, há um desafio a ser aceito por todos: superar, por incorporação, as especificidades, que devem agora ser associadas à totalidade, numa visão pós-moderna de ciência e de co- nhecimento. Ou seja, o caminho do todo às partes, aprofundando-se as especificidades das áreas, deve ser complementado com o caminho de volta, das partes ao todo, enredandoas num contexto significativo.

Outro elemento fundamental nessa evolução da individualização para a ação grupal, do trabalho parcelado e fragmentado para um trabalho relacional, da superação da racionalidade cartesiana, tem sido buscado na compreensão da teoria da complexidade, apresentada por diferentes autores. Os estudos dos textos de Morin (1999), Santos (1999), Capra (1996), Khun (1994) e outros têm sido essenciais nos processos de desenvolvimento pessoal, profissional e institucional. Sem a pretensão de sintetizar o que é complexo, como aquilo que é tecido junto, destacamos vários elementos que, pontuados pelos autores citados, têm auxiliado na compreensão de um pensar dialético e na superação de uma visão formal de ciência, conhecimento e saber escolar, estrutura curricular e ação docente e discente, buscando superar nossa visão linear do isto ou aquilo pela lógica do isto e aquilo.

Consideramos ser um desafio tomar como objeto de estudo a apreensão da globalidade, $a$ superação da visão fragmentada, o vínculo entre o todo e as partes, o desenvolvimento do espírito para a contextualização, o estabelecimento de relações e percepção das reciprocidades, buscando restaurar a unidade complexa da na- 
tureza humana, estabelecendo a condição humana e a era planetária como objeto essencial do ensino. Ao se fazer isso, discute-se a comunicação, a dominação e a opressão entre os povos, além de situar-se a educação na zona das incertezas, ensinando princípios de estratégias que permitam lidar com o imprevisto, o inesperado e o incerto como elemento vital entre os seres humanos e, também, estudando a incompreensão a partir de suas raízes, modalidades, efeitos, da antropo-ética (MORIN, 2000).

A discussão sobre os Projetos Institucionais Pedagógicos e os Projetos de Cursos permite um novo olhar acerca dos fins, valores, formas de organização e efetivação da formação universitária proposta e efetivada por nós, docentes, com os alunos. Chega-se à sala de aula, à relação com os saberes escolares, ao caminho traçado pelos docente e discentes, a partir de olhares diversos que nos auxiliam a rever as ações pessoal, profissional e institucional. São ações que, por sua própria natureza, não comportam uma lógica de previsibilidade positivista (CONTRERAS, 1977), inadequada a certas práticas profissionais, como é o caso da docência, que enfrenta situações incertas, conflitos, efeitos ambíguos, não aceitando transposições de regras de decisão, modelos ou formatações.

Os processos de profissionalização continuada vivenciados e aqui citados são espaços institucionais de fortalecimento das identidades, pes- soais e profissionais e da própria categoria docente. As alterações constatadas resultam em proveito para os sujeitos envolvidos, professores e alunos, e para o próprio processo de ensino e de aprendizagem, possibilitando sistematizações importantes sobre a ação docente universitária hoje necessária.

\section{REFERÊNCIAS}

ANAStASIOU, L. G. C. Metodologia do ensino superior: da prática docente a uma possível teoria pedagógica. Curitiba: IBPEX, 1998.

Desafios de um processo de profissionalização continuada: elementos da teoria e da prática. Revista Saberes, Rio de Janeiro, v. 1, n. 1, mai./ago. 2000.

Educação superior e preparação pedagógica: elementos para um começo de conversa. Revista Saberes, Rio de Janeiro, v. 2, n. 1, mai./ago. 2001.

Metodologia de ensino na universidade brasileira: elementos de uma trajetória. In: CASTANHO, M. E.; CASTANHO, S. Temas e textos em metodologia do ensino superior. Campinas: Papirus, 2001.

Docência como profissão no ensino superior e os saberes científicos e pedagógicos. Educação e Cultura, Joinvile, v. 7, n. 1, jun. 2002.

; PIMENTA, S. G.; CAVALLET, V. J. Docência no ensino superior: construindo caminhos. In: SEVERINO, J.; FAZENDA I. C. (Orgs.). Formação docente: rupturas e possibilidades. Campinas: Papirus, 2002. 
; PIMENTA, S. G. Docência no ensino superior. São Paulo: Cortez, 2002.

CAPRA. F. A teia da vida: uma nova compreensão científica dos sistemas vivos. São Paulo: Cultrix, 1996

CONTRERAS, J. L'autonomia del profesorado. Madrid: Morata, 1977.

KHUN, T. A estrutura das revoluções científicas. São Paulo: Perspectiva, 1994.

MASETTO, M. T. (Org.). Docência na universidade. Campinas: Papirus, 1998.

MEIRIEU, P. Aprender... sim, mas como? Porto Alegre: Artes Médicas, 1998.

MORIN, E. Os sete saberes necessários a educação do futuro. São Paulo: Cortez; Brasília, DF: UNESCO, 2000.

. Epistemologia da complexidade. In: SCHNITMAN, D. F. (Org.). Novos paradigmas culturais, cultura e subjetividade. Porto Alegre: Artes Médicas, 1999.

NIAS, J. Changing times, changing identities: grieving for a lost self. In: NÓVOA, A. (Org.). Vidas de professores. Porto Editorial, 1992

NÓVOA, A. (Org.). Vidas de professores. Porto, Pt: Porto Editorial, 1992.

PERRENOUD, P. Práticas pedagógicas, profissão docente e formação: perspectivas sociológicas. Lisboa: Dom Quixote/ IIE, 1993.

PESSATE ALVES, L. A construção do projeto político pedagógico na educação superior. Dissertação (Mestrado em Educação), Pontifícia Universidade Católica do Paraná, Curitiba, 2000

PIMENTA, S. G. Formação de professores: saberes e identidade. In: PIMENTA, S. G. (Org.). Saberes pedagógicos e ati- vidade docente. São Paulo: Cortez, 1999. ; GARRIDO, E; MOURA, M. O. $\overline{\text { Pesquisa colaborativa na escola como abor- }}$ dagem facilitadora para o desenvolvimento profissional do professor. In: MARIN, A. M. (Org.). Educação continuada. Campinas: Papirus, 2000.

SACRISTÁN, G. J. Poderes instáveis em educação. Porto alegre: Artes Médicas, 1999.

SANTOS, B. S. Um discurso sobre as ciências. Porto: Afrontamento, 1999.

SEVERINO, A. J. Metodologia do trabalho científico. São Paulo: Cortez, 1996.

Encaminhado em 25/04/05

Aceito em 08/06/05 